\title{
"Difficult back", turns into "less difficult back" by ultrasonography
}

\author{
Yoon-Hee Kim \\ Department of Anesthesiology and Pain Medicine, College of Medicine, Chungnam National University, Daejeon, Korea
}

Despite the accumulation of medical experience, better training, advanced equipment and safer local anesthetics, the incidence of neurological complications after central neuraxial blockade has not decreased [1]. Several explanations have been suggested, including the increased popularity of regional anesthesia as well as the increasing prevalence of risk factors (e.g., obesity [2], diabetes [3], and potent anticoagulant [4]).

Neurological complications after a central neuroaxial blockade can occur due to "non-anesthetic" or "probable anesthetic" causes. "Non-anesthetic" causes include surgical position, trauma, and compression by tourniquet or casts, etc. "Probable anesthetic" causes include traumatic injury during needle or catheter insertion, spinal cord ischemia, infection and toxicity of anesthetic drugs.

Among the "probable anesthetic" causes, traumatic injury needs special attention. Needle trauma can easily lead to neurological complications. Multiple traumatic attempts during needle placement are widely known to be related to higher incidence of epidural hematoma [3,5]. The Norwegian Association of Anaesthesiologist' guidelines for central neuraxial blockade in patients with potential bleeding problems specifically mention the need for a competent and "atraumatic" anesthesiologist [3]. Owens et al. [6] reviewed six reports of spinal hematomas after spinal anesthesia. In the five cases for which comments were available, four of the five were termed a "difficult tap".

Also, multiple needle attempts can cause postdural puncture headaches [7] and is a contributing factor for postoperative back pain $[8,9]$. It is known to be the main cause of patient dissatisfaction and refusal for additional central neuraxial blocks [10].
Accordingly, in order to prevent a less experienced provider from performing a prolonged, traumatic and painful procedure, it is necessary to precisely identify a "difficult back". Identification can also provide an opportunity to switch the type of anesthesia in advance.

Anesthesiologists have long recognized the importance of identifying patients with significant risks prior to treatment, including difficult airways [11], protamine anaphylaxis [12] and malignant hyperthermia [13].

However, in spite of the risks of severe complications, very few studies evaluate the factors that can potentially cause technical problems when performing a central neuraxial blockade.

In the Korean Journal of Anesthesiology, Kim et al. [14] studied 253 patients scheduled for elective surgery under spinal or epidural blockade. Kim et al. [14] evaluated the predictors of a "difficult back" by using the number of attempts during a neuraxial block as a measure of difficulty. They reported that the depth of the subarachnoid or epidural space and the provider's level of experience are related to the difficulty in performing a neuraxial blockade. However, one must consider the method used in order to measure the depth of the subarachnoid or epidural space in the Kim et al. [14] study. Kim et al. [14] measured the depth of the subarachnoid or epidural space by measuring the length from the skin to the needle hub and subtracting this from the total length of the needle. This cannot be considered as an objective measurement.

Firstly, the approach method was not unified. The authors mentioned that the approach method was not considered

Corresponding author: Yoon-Hee Kim, M.D., Ph.D., Department of Anesthesiology and Pain Medicine, College of Medicine, Chungnam National University, Munhwa-ro, Jung-gu, Daejeon 301-721, Korea. Tel: 82-42-280-7840, Fax: 82-42-280-7968, E-mail: yhkim0404@cnu.ac.kr (c) This is an open-access article distributed under the terms of the Creative Commons Attribution Non-Commercial License (http:// creativecommons.org/licenses/by-nc/3.0/), which permits unrestricted non-commercial use, distribution, and reproduction in any medium, provided the original work is properly cited. 
due to the point that using only one approach method is not only impractical, but it is also impossible to perform a precise median or paramedian approach in discusssion section.

Although this is somewhat true, the insertion depth would mostly be deeper in the paramedian approach. Furthermore, the insertion depth would mostly be deeper in the paramedian approach. The needle insertion site can also affect the depth of the needle due to the large lumbar interspinous space. The insertion angle of the needle is also important since even a small change in angle can affect the needle trajectory. Different block patterns used by different anesthesiologists can also reduce the objectivity of measurements.

The depth of the subarachnoid or epidural space can be measured accurately by MRI or ultrasound with the patient in the same position. Objectivity can be achieved even when measuring with the needle if the needle trajectory is controlled by adjusting the insertion point and angle by ultrasound as shown in the study conducted by Balki et al. [15].

In previous studies that identify factors related to difficult central neuraxial blocks, many researchers regard the quality of anatomical landmarks (related to BMI) and the distance from skin to subarachnoid or epidural space as the predictor of difficulty [16-19].

Poor landmark can especially interfere with accurate interspace identification and lead to conus medullaris injury [20-22]. The classical teaching is that the spinal cord ends at L12 , but it has been known for over half a century that this is the mean position of a normal distribution. Several series describe the spinal cord extending to the body of L3 in $1-3 \%$ of patients, and to L2 or lower in almost $50 \%$ of patients, with increased variability in women [23]. As suspected by many clinicians, precise lumbar interspace identification by palpation is prone to error. Broadbent et al. [24] confirmed this, showing that anesthetists were $29 \%$ accurate, as determined by MRI.

Recent studies clearly show that ultrasound-guided techniques can reduce the technical difficulty of neuraxial blockade in patients with difficult anatomic landmarks even in the hands of experienced anesthesiologists [25-31]. Although the relatively deep epidural space and interfering bone structures limit the potential of ultrasound-guided epidural puncture, benefits such as the estimation of the depth to the intrathecal or epidural space can be quite useful [32]. Accurate identification of the intervertebral levels may also reduce the risk of conus medullaris injury.

In summary, the attempt by Kim et al. [14] to investigate difficulty predictors during central neuraxial block is quite meaningful for a safer and higher quality neuraxial block. We also believe that ultrasonography can definitely help to solve Kim et al.s and our concern.

\section{References}

1. Auroy Y, Narchi P, Messiah A, Litt L, Rouvier B, Samii K. Serious complications related to regional anesthesia: results of a prospective survey in France. Anesthesiology 1997; 87: 479-86.

2. Nielsen KC, Guller U, Steele SM, Klein SM, Greengrass RA, Pietrobon R. Influence of obesity on surgical regional anesthesia in the ambulatory setting: an analysis of 9,038 blocks. Anesthesiology 2005; 102: 181-7.

3. Renck H. Neurological complications of central nerve blocks. Acta Anaesthesiol Scand 1995; 39: 859-68.

4. Vandermeulen EP, Van Aken H, Vermylen J. Anticoagulants and spinal-epidural anesthesia. Anesth Analg 1994; 79: 1165-77.

5. Lerner SM, Gutterman P, Jenkins F. Epidural hematoma and paraplegia after numerous lumbar punctures. Anesthesiology 1973; 39: 550-1.

6. Owens EL, Kasten GW, Hessel EA 2nd. Spinal subarachnoid hematoma after lumbar puncture and heparinization: a case report, review of the literature, and discussion of anesthetic implications. Anesth Analg 1986; 65: 1201-7.

7. Flaatten H, Berg CM, Brekke S, Holmaas G, Natvik C, Varughese K. Effect of experience with spinal anaesthesia on the development of post-dural puncture complications. Acta Anaesthesiol Scand 1999; 43: 37-41.

8. Choi JG, In JY, Shin HI. Analysis of factors related to patient refusal of spinal anesthesia. Korean J Anesthesiol 2009; 56: 156-61.

9. Horlocker TT, McGregor DG, Matsushige DK, Schroeder DR, Besse JA. A retrospective review of 4767 consecutive spinal anesthetics: central nervous system complications. Perioperative Outcomes Group. Anesth Analg 1997; 84: 578-84.

10. Rhee WJ, Chung CJ, Lim YH, Lee KH, Lee SC. Factors in patient dissatisfaction and refusal regarding spinal anesthesia. Korean J Anesthesiol 2010; 59: 260-4.

11. Mallampati SR, Gatt SP, Gugino LD, Desai SP, Waraksa B, Freiberger $\mathrm{D}$, et al. A clinical sign to predict difficult tracheal intubation: a prospective study. Can Anaesth Soc J 1985; 32: 429-34.

12. Levy JH, Schwieger IM, Zaidan JR, Faraj BA, Weintraub WS. Evaluation of patients at risk for protamine reactions. J Thorac Cardiovasc Surg 1989; 98: 200-4.

13. Larach MG, Localio AR, Allen GC, Denborough MA, Ellis FR, Gronert GA, et al. A clinical grading scale to predict malignant hyperthermia susceptibility. Anesthesiology 1994; 80: 771-9.

14. Kim JH, Song SY, Kim BJ. Predicting the difficulty in performing a neuraxial blockade. Korean J Anesthesiol 2011; 61: 377-81.

15. Balki M, Lee Y, Halpern S, Carvalho JC. Ultrasound imaging of the lumbar spine in the transverse plane: the correlation between estimated and actual depth to the epidural space in obese parturients. Anesth Analg 2009; 108: 1876-81.

16. de Filho GR, Gomes HP, da Fonseca MH, Hoffman JC, Pederneiras SG, Garcia JH. Predictors of successful neuraxial block: A prospective study. Eur J Anaesthesiol 2002; 19: 447-51.

17. Sprung J, Bourke DL, Grass J, Hammel J, Mascha E, Thomas P, et al. Predicting the difficult neuraxial block: A prospective study. Anesth Analg 1999; 89: 384-9.

18. Ellinas EH, Eastwood DC, Patel SN, Maitra-D'Cruze AM, Ebert TJ. The effect of obesity on neuraxial technique difficulty in pregnant 
patients: A prospective, observational study. Anesth Analg 2009; 109: 1225-31.

19. Atallah MM, Demian AD, Shorrab AA. Development of a difficulty score for spinal anaesthesia. Br J Anaesth 2004; 92: 354-60.

20. Collier CB, Gatt SP. More reports of spinal cord damage by spinal needles. Anaesth Intensive Care 2002; 30: 532.

21. Reynolds F. Logic in the safe practice of spinal anaesthesia. Anaesthesia 2000; 55: 1045-6.

22. Reynolds F. Damage to the conus medullaris following spinal anaesthesia. Anaesthesia 2001; 56: 238-47.

23. Reimann F, Anso BJ. Vertebral level of termination of the spinal cord with report of a case of sacral cord. Anat Rec 1944; 88: 127-38.

24. Broadbent CR, Maxwell WB, Ferrie R, Wilson DJ, Gawne-Cain M, Russell R. Ability of anaesthetists to identify a marked lumbar interspace. Anaesthesia 2000; 55: 1122-6.

25. Grau T, Leipold RW, Conradi R, Martin E. Ultrasound control for presumed difficult epidural puncture. Acta Anaesthesiol Scand 2001; 45: 766-71.

26. Cork RC, Kryc JJ, Vaughan RW. Ultrasonic localization of the lumbar epidural space. Anesthesiology 1980; 52: 513-6.
27. Grau T, Leipold R, Conradi R, Martin E, Motsch J. Ultrasonography and epidural anaesthesia: technical possibilities and boundaries of ultrasonic examination of the epidural space. Anaesthesist 2001; 50 : 94-101.

28. Grau T, Leipold RW, Conradi R, Martin E, Motsch J. Ultrasound imaging facilitates localization of the epidural space during combined spinal and epidural anesthesia. Reg Anesth Pain Med 2001; 26: 64-7.

29. Arzola C, Davies S, Rofaeel A, Carvalho JC. Ultrasound using the transverse approach to the lumbar spine provides reliable landmarks for labor epidurals. Anesth Analg 2007; 104: 1188-92.

30. Furness G, Reilly MP, Kuchi S. An evaluation of ultrasound imaging for identification of lumbar intervertebral level. Anaesthesia 2002; 57: 277-80.

31. Stamatakis E, Moka E, Siafaka I, Argyra E, Vadalouca A. Prediction of the distance from the skin to the lumbar epidural space in the Greek population, using mathematical models. Pain Pract 2005; 5: 125-34.

32. Whitty R, Moore M, Macarthur A. Identification of the lumbar interspinous spaces: Palpation versus ultrasound. Anesth Analg 2008; 106: 538-40. 